\title{
LOS POPOL VUH
}

Munro S. Edmonson Tulane University

Bajo la rúbrica de trabajo en proceso quiero presentar aquí en forma preliminar la traducción e interpretación de dos textos mayas, uno del comienzo del Popol Vuh de los quichés y el otro del comienzo del Libro de Chilam Balam de Tizimín de los yucatecos. Mi propósito es demostrar que los dos comparten una estructura literaria típicamente mesoamericana (presente, por ejemplo, también en náhuatl), que es a la vez obstáculo y llave de su clarificación. Creo que el debido entendimiento de esta estructura abre un panorama bastante halagüeño de las posibilidades de reinterpretación de los textos yucatecos. Incluso no considero imposible que tal reinterpretación pudiera proporcionarnos otros Popol Vuh, o sea fuentes a un mismo tiempo históricas, literarias y culturales, para profundizar nuestra comprensión del enigma siempre actual de los mayas.

Carecemos, en el caso maya, de la ventaja enorme de una obra como la de Sahagún en náhuatl. Aun las aportaciones valiosísimas de un Ximénez o de un Landa no llegan a abrimos una ventana que dé directamente a las cuestiones de estilística literaria. En otro lugar (Edmonson, 1971, passim), he presentado mis argumentos para considerar que los pueblos mesoamericanos tienen en común un mismo sistema de estilo formal, o sea el difrasismo: la formación de coplas semánticas, un género comúnmente llamado paralelismo. Sólo en náhuatl se ha reconocido un segundo nivel de estructura metafórica, llamado por el padre Garibay (1953) difrasismo: el uso de dos imágenes verbales para significar otra tercera, a menudo bastante diferente. Un uso semejante aparece también en otras partes del mundo, incluso en la tradición épica anglosajona, donde se denomina kenning.

En Beowulf las metáforas llegan a ser bastante complicadas. "El camino de los pescados", por ejemplo, sirve para decir "el mar". 
Clarificación,

Y explicación,

De lo escondido

E iluminado

Por el Formador,

El Modelador,

Paridera

Y Engendrador por nombre,

Cazador Tacuazín

Y cazador Coyote,

Gran Jabalí Blanco

Y Pisote,

Majestad

Y Quetzal Serpiente,

Corazón del Lago

Y corazón del Mar,

El del Plato Azul

Y el de la Copa Azul,

También llamados,

También dichos

La que tiene nietos

$\mathrm{Y}$ el que tiene nietos,

$\mathrm{Xpiacoc}$

Y Xmucane por nombre,

Abrigo

Y Protegedor,

Bisabuela

Y Bisabuelo,

Como se dice

En palabra quiché

Pues dijeron todo

Y lo hicieron

En la existencia clara

$\mathrm{Y}$ palabrà clara

(Edmonson, 1971:3-6)

Justifico en otra parte (Edmonson, op cit.) mis preferencias respecto a esta traducción. He tratado de seguir muy de cerca el texto quiché. Lo que sigue interpreta, en forma de prosa, la estructura poética, dando la significación "escondida" de cada copla. 
$\mathrm{El}$ oro es el tesoro brillante, míticamente localizado en el fondo del mar, entonces es "candelas del camino de los pescados". El que es rico es rey, así que el rey es "poseedor de las candelas del camino de los pescados". Los ejemplos en náhuatl son generalmente más sencillos. "Flor y canto" constituyen poesía; "soga y cuerda" son cautiverio.

Muchos de los difrasismos que se emplean en el Popol Vuh me parecen préstamos del náhuatl. Otros pueden ser quizá figuras mayas. En todo caso, son bastante frecuentes, y revelan todo un nivel de significación que va más allá de la traducción de palabras aisladas. Así, "cerro y valle" implica la patria chica, el pueblo natal; "nacido y engendrado" quiere decir la nobleza, los hijos de algo; contrariamente, "huérfanos de madre y padre" son los campesinos, $\mathrm{y}$, "hermanos mayores y menores", es igual a todo el mundo, tanto noble como común. En la tradición quiché estas expresiones, por frecuentes que sean, están empleadas, podríamos decir, casi decorativamente. Sin embargo, hay momentos en que pueden impedir el claro entendimiento de una frase.

Otro es el caso del yucateco. Me parece natural que la tradición clásica de Yucatán haya producido un estilo literario casi churrigueresco, en donde la sustitución de ideas se complica hasta llegar a menudo a la incomprensibilidad. Ofrezco aquí un ejemplo comparativo de este mecanismo en quiché y yucateco. Para aclarar el caso doy dos niveles de traducción: el primero más o menos literal y palabra por palabra; el segundo, interpretativo, copla por copla. Se verá que, en el caso quiché, este modo de presentación puede iluminar cosas accesibles, pero latentes en el texto básico. En yucateco, es más, la "interpretación" es imprescindible para el entendimiento mismo.

El Popol Vuh comienza con las líneas siguientes:

Esto es la raíz de la palabra antigua.

Este es quiché por nombre.

Aquí escribiremos,

Comenzaremos ya palabras antiguas,

Los comienzos

$\mathrm{Y}$ arraigos

De todo lo hecho en el pueblo Quiché,

Por el pueblo de la gente quiché,

Así que esto es lo que uniremos:

El desciframiento, 
Esto es la fuente de los misterios

De la antigua tradición escrita,

$\mathrm{El}$ origen

Del pueblo de los misterios

Redactado

Y explicado;

Los secretos revelados

Del Creador

Y Autor

Del albor

Y luz,

Señor

Y Esencia

Del tiempo,

También llamado

Abuelo

Y Bisabuelo (en náhuatl),

Protegedor

Y Bisabuelo

En quiché,

Omnipotente

En gloria.

No todas las coplas pueden ser interpretadas rigurosamente, y se concede que algunas son francamente puras suposiciones. En algunos casos, sin embargo, tengo cierta confianza en el resultado.

La forma poética misma nos advierte que la expresión "Quiché" (literalmente "muchos árboles", de donde -en náhuatl-Guatemala) se entiende por una referencia a la "raíz de la palabra antigua", o sea el misterio central de la tradición maya: el origen de las cosas, el tiempo, y la escritura. Está subrayado después (1.6) que la raíz de algo es su origen, y otras partes del mismo Popol Vuh parecen indicar que la "palabra antigua" es la escritura glífica.

Cazador (1.20) o Hun $\mathrm{Ah} \mathrm{Pu}$ es el último de los veinte días (el Ahau yucateco), mientras que el tacuazín está identificado con el amanecer. No sé cuál sea la asociación correspondiente al coyote, pero adivino que la referencia corresponde al milagro diario del fin-y-comienzo del sol. De manera semejante, aunque carecemos de base para interpretar cosmológicamente al jabalí y al pisote, la referencia a lo blanco me sugiere luz. El "plato y copa" (1.28) son instrumentos sagrados para la adivinación y la cuenta del año, 
así que simbolizan "el tiempo". Xpiacoc y Xmucanè son expresiones en náhuatl para decir los bisabuelos.

A pesar de que quedan algunas dificultades e interrogantes, me parece evidente que el texto del Popol Vuh se presenta envuelto en difrasismos, y que una parte importante de su significación está contenida en ellos.

El Libro de Chilam Balam de Tizimín (Roys, s.f.) comienza con las líneas siguientes, que pueden considerarse, quizá, una de las partes más tradicionales de toda la literatura colonial de Yucatán:

$13 \mathrm{~K}^{\prime} a \mathrm{n}^{1}$

El primero de Pop

Se tomó el plato del $k^{\prime} a t u n^{3}$

Que era 5 Ahav.

El año 1593 ocurrió. ${ }^{5}$

En 15 Tzek amaneció.

$\mathrm{Y}$ el relato de los acontecimientos

Se contará como sigue.

Era la luna

al sol. ${ }^{10}$

Fué la creación

De este k'atun.

Mayapán era la cara ${ }^{13}$

Del cambio del $k^{\prime} a t u n$,

$\mathrm{Al}$ sol

De la bajada

Del hijo del quetzal,

Del hijo de la paloma; ${ }^{18}$

$\mathrm{Al} \mathrm{sol}$

Y luna

De los nacidos

Y engendrados. ${ }^{22}$

Al tiempo había tres pirámides de piedra,

Las paredes de piedra de $A k^{\prime} a b P^{\prime} e x$

En los tres prados decaídos,

Los tres suelos en la vecindad de Yaxché, ${ }^{26}$

$\mathrm{Al} \mathrm{sol}$

Y luna

Estuvo blanco ${ }^{29}$

A la orilla del mar. 

$\mathrm{Al}$ sol hubo la pista
De los cuatro dioses de lluvia ${ }^{32}$
Parados al abierto ${ }^{33}$
Y parados a la orilla del agua salada.
Ya ido
Lo escrito
$\mathrm{Al}$ medio del $k^{\prime}$ atun $11 \mathrm{Ahav},{ }^{37}$
La luna del tiempo del $k^{\prime} a t u n$.
Ya viene:
La actualización de la palabra
Del del arbolito
El ojo del sol del (arbol)ito ${ }^{42}$
Quien nació
Y volvió al cielo.
Esta será su palabra.
Ya es $13 K^{\prime}$ an.

En las notas (enumeradas por líneas), se encontrarán algunas aclaraciones de la cronología y lingüística de este texto. Constituye la descripción del primero de una veintena de años (hab), comenzando en 1593. Se escribió en la vecindad de Bacalar el 15 de febrero de 1596. He aquí su contenido latente:

\section{En 1593}

Fue la confirmación del $k^{\prime} a t u n 5$ Ahav

El 23 de octubre de 1593.

Esta es su historia.

Con el fin al comienzo,

Un nuevo $k^{\prime} a t u n$

Inventado en Mayapán:

El comienzo de la caída

De los matrilinajes toltecas;

Dentro de la época

De la nobleza maya

Había tres pirámides de $A k^{\prime} a b P^{\prime} i x$,

Hoy las ruinas cerca de Yaxché.

$\mathrm{Al}$ fin

Volvió al norte a Emal

Comenzando las ceremonias del cargador del año

En la plaza junto al mar

Y la profecía salió

De la última mitad del $k^{\prime} a t u n 11$ Ahav. 
La palabra nueva será cumplida

De Jesús

Y la Ascensión.

Esta es la palabra de 1593.

Recurre aquí el difrasismo de "sol y luna", principalmente para representar comienzo y fin. "Quetzal y paloma" parece significar linajes nobles del occidente de Yucatán, además identificados por ascendencia materna. "Nacidos y engendrados" son los nobles, como en quiché, implicando alguna ascendencia notable, tanto paterna como materna. Otras expresiones se explican en las notas.

Hay también metáforas y símbolos que no toman forma dualística. Mayapán es la "cara" del cambio del k'atun; es la persona, el responsable. "Agua salada" es el mar. "Blanco" significa norte. "Tomar el plato del k'atun" quiere decir confirmarse en el sacerdocio, cinco años antes de iniciarse la veintena, porque así era el rito.

No cabe duda de que este estilo involucrado era el establecido y tradicional en Yucatán. Nos acordamos de la "Lengua de Zuyua" descrita en el Libro de Chilam Balam de Chumayel (Roys, 1965: 88-98), las adivinanzas rituales que constituían las pruebas de la legitimidad y formación de los oficiales. No he descubierto ningún caso del uso del simbolismo de las adivinanzas en otros textos yucatecos. Sin embargo, la tendencia yucateca era obviamente decir una cosa y significar otra. El resultado tiene cierta belleza y elegancia, no obstante que torna difícil su entendimiento para otra época $\mathrm{u}$ otra cultura.

En cuestión de grado, el simbolismo verbal del yucateco excede en mucho al del quiché. Su mecanismo permanece invariable. Me parece comprensible que la diferencia corresponda al aislamiento relativo y a la pobreza cultural de los quichés del Posclásico -más limitado su calendario y acortado su sistema de adivinación. Los sacerdotes quichés impresionaban a sus súbditos campesinos mediante hazañas de magia y con el despliegue de fuerza militar. En Yucatán había más distancia social entre las clases, y los sacerdotes gobernaban mediante milagros más profundos escondidos en un idioma más oracular.

El texto presentado del libro de Tizimín se ha considerado profético. $\mathrm{Y}$ en cierto sentido lo es. Resulta evidente que es también histórico. Forma parte de un texto de 1410 líneas (705 coplas), el cual, a su vez, constituye como una cuarta parte del libro de Tizimín. El texto total es de interés extraordinario. Tengo proyec- 
tada la publicación de una traducción completa del libro entero, debidamente anotada. Entre tanto me contento con una consideración preliminar de este primer texto, que puede nombrarse el de 5 Ahau Oxlahun K'an.

Como suele pasar con todo lo que atañe a los mayas, el núcleo del problema es el tiempo. El $t z o l$ k'in, o ciclo de 260 días, en todo el libro de Tizimín se conforma bien con el clásico. Los ciclos mayores no. Hay una diferencia de dos días en los cargadores del año, y hay, además, un cambio, descrito en el texto citado, en la denominación de los $k^{\prime} a t u n o b$ (veintenas de ciclos de 360 días), los cuales están aquí nombrados por fecha inicial en vez de final. Además hay contradicciones respecto a la correlación con el calendario gregoriano.

$\mathrm{El}$ autor de nuestro texto dice haberlo terminado el $15 \mathrm{de}$ febrero de 1544. Pero, aparte de lo increíble de esta fecha en sí, el texto mismo comienza con 1593. Al final del Tizimín hay otra correlación indirecta en un calendario, que ofrece las fechas cristianas diarias para tres años (no identificados), con los mismos cargadores del año de nuestro texto. Suponiendo que la fecha de 1593 es la correcta, y que la cuenta de cargadores del año se haya mantenido, éstos son de 1777, 1778 y 1779. Si el calendario en cuestión fue escrito en 1779, se puede inferir la fecha exacta del comienzo del año $13 \mathrm{~K}$ 'an de nuestro relato, así como la fecha de su composición, a saber, el 15 de febrero de 1620. Tengo documentado en otra parte (Edmonson, s.f.) que la fecha verdadera de este texto es 15 de febrero de 1596. Intenta ser la profecía para la veintena de 1593 a 1613 . Pero es profecía enteramente sistemática, que se basa en la historia escrita del período anterior, comenzando con el mismo cargador del año en 154l. Resulta que nos ofrece la historia de 1541 a 1561 como una historia que tiene que repetirse 52 años después.

La cronología del Tizimín implica un ciclo de 52 hab (años de 365 días), que comienza quizá en 1581 con el día $1 K^{\prime}$ an O Pop. La correlación GMT daría un ciclo que comienza en 1553 con $1 I^{\prime} k^{\prime}$ O Pop. La diferencia se debe a un cambio calendárico instituído en 1539 (Edmonson, en prensa). Es notable que el énfasis de nuestro texto subraye la importancia de este ciclo ( $k^{\prime}$ in tun y abil), mismo que usaban los aztecas, y no el ciclo de tunob y katunob.

El texto de Oxlahun $K^{\prime}$ an trata del ciclo de 52 años en forma histórica y profética, y del ciclo de 20 años (el k'atun) en forma ritual. Al mismo tiempo expresa la gran sensibilidad de los mayas al calendario europeo, una novedad que les habrá impresionado 
como una amenaza a todo lo que era el orden de su cultura. Me recuerda la sensibilidad que tenían los escoceses al momento de su cristianización (según el Venerable Beda), cuando rechazaron violentamente la nueva Pascua romana durante décadas. En el caso maya, era tal la preocupación con el asunto calendárico, que, desde el punto de vista maya, toda la conquista española podría tener justamente el nombre de Guerra del Calendario.

El Oxlahun $K^{\prime}$ an es un tratado sutil sobre esta realidad. Refleja, además, cierta incertidumbre, orgánica a todo el libro de Tizimín, en relación a la esfera debida de los cuatro ciclos principales conocidos: 1) el $t z^{\prime}$ ol kin de 260 días, 2) el tun de 360 días, 3) el hab de 365 días, y 4) el año de 365 días, más el bisiesto. La interpretación de este misterio constituye, en cierto sentido, la historia maya colonial.

Para el autor del Oxlahun $K^{\prime}$ an lo importante era esa especie de talla entre el tun y el hab. El tun regía la vida ceremonial (pero, tras eso, la vida económica y política); el hab era la entidad profética y, por lo tanto, histórica. Resulta que estamos frente a una crónica de actos ceremoniales (fechados conforme al tun), localizados en cierto momento histórico (según el año); pero, mucho más radicalmente, en un momento dado del ciclo profético $(h a b)$. El pequeño ciclo adivinatorio ( $\left.t z o l k^{\prime} i n\right)$ está presente, pero con disminuida influencia.

El texto mismo insiste en que éste es el relato de 1593-1613. Gran parte del contenido me parece más apropiado para la veintena precisamente del ciclo (de $52 \mathrm{hab}$ ) anterior, o sea, de 1541-1561; aunque, desde el punto de vista del autor, esto casi no tenía importancia, ya que tenía confianza de que los hechos de una rueda del calendario ( $k^{\prime}$ in tun y abil ó $52 \mathrm{hab}$ ) predecían siempre los de la siguiente. En esto, el sistema no es el de los mayas clásicos, sino el de los aztecas, cuya influencia era muy marcada, tanto en Yucatán como en Guatemala, desde el siglo XII al siglo XV.

Las profecías tradicionales de los mayas estaban ligadas a] $k^{\prime} a t u n$, y no al $h a b$. De allí que estemos aquí frente a un sistema mixto. El tzol k'in sigue siendo adivinatorio; el tun y $k^{\prime} a t u n$ se han vuelto rituales; el hab es ya profético y el año es histórico.

Comencemos con lo histórico. El Oxlahun $K^{\prime}$ an dice que llegó. el cristianismo en 1541, y el calendario español, junto con las leyes: de indumentaria, en 1542. En 1543, había impuestos y la consecuente rebelión. En 1544, llegaron los misioneros (no se dice a dónde) y hubo más rebelión. Aunque ésta se menciona sólo como. una parte de la guerra que continuaba desde 1522 a 1596 . En 1545 , 
vino la caída de 7 Chuah, pero la guerra civil seguía, causando migraciones y hambre en 1546. En 1547, hubo una restauración maya, encabezada por 7 Corazón Venado, provocando los tres años de guerra que van de 1548 a 1551. 7 Corazón Venado logró tomar posesión de su cargo para la segunda mitad del $k^{\prime} a t u n$ en 1552, librando el sitio sagrado de Mayapán de los cristianizados, por primera vez en unos veinte años; pero, reaparecieron los misioneros, y la lucha se reanudó, extendiéndose al occidente en 1553 y, al norte, en 1554. 7 Corazón Venado fue derrotado en 1555 y, en 1556, le sucedió Sol Ojo, parece que con una política también tradicionalista. Llegado (en 1557) el último cuarto del $k^{\prime} a t u n$, se suspendieron los títulos de tierra, lo cual intensificó la lucha política. Uxmal volvió al sacrificio en 1558, y durante el año siguiente Corazón Venado anunció su conversión al cristianismo. Los anticristianos del noreste lo reemplazaron con 2 Codorniz, de Emal, en 1560. Llegado el nuevo cuarto del $k^{\prime}$ atun (de 1614), parece que se instaló un candidato de compromiso para resolver la división del oriente maya y el occidente cristianizado. Fue 8 Corazón Dios. Con eso, se pudo terminar la distribución de tierras e iniciar el nuevo $k^{\prime} a t u n$, ceremonialmente, fuera de las ruinas de Mayapán.

Es notable que este relato dé poco espacio a los españoles. Trata principalmente de la división ideológica entre los mayas. Como resultado, son pocos los detalles que pudieran haber atraído la atención de los cronistas españoles. Se menciona un huracán en 1549 (1601?), y un eclipse en 1552 (1607?). Se habla de entradas de misioneros en 1544 y 1552, pero ¿por dónde? No hay ninguna referencia a soldados españoles.

$\mathrm{El}$ autor del Oxlahun $K^{\prime}$ an es claramente partidario de la facción tradicionalista de la nobleza, un tal $K^{\prime}$ auil $C h^{\prime} e l$, identificado también con la tradición de los profetas y con el oriente, particularmente Bacalar. Hace contraste entre la tradición oriental Itzá, y la occidental de la gente de los cerros (por ejemplo, Tutul Xiu), a la cual considera bárbara y ajena. Dice textualmente que este relato traduce lo que leía en los glifos. Considero, por eso, como muy probable la fecha de 1541-1561 para el relato glífico. Queda, sin embargo, el problema de los $k^{\prime}$ atunob.

$K^{\prime}$ auil $C h^{\prime} e l$ nos proporciona una visión bastante clara del ciclo ceremonial, tanto normal como trastornado por la guerra religiosa. Como en el calendario católico, había dos clases de fiestas: una apegada al año solar ( $h a b)$; la otra, al sagrado (tun). El año solar comenzaba con las ceremonias del año nuevo. Incluía seguramente las fiestas de los dioses patrones de los meses (uinal), de las cuales 
no se hace mención. Nota el año agrícola (apenas mencionado de paso) y los solsticios (mencionados brevemente). Y termina con los días nefastos de Uayeb, el apagar de los fuegos en preparación para el fuego nuevo del año siguiente.

Las ceremonias del tun y del $k^{\prime} a t u n$ las representa como más importantes. El $k^{\prime}$ atun comienza con la instalación de nuevos oficiales, tanto religiosos ( $a h k^{\prime} i n$ ) como políticos (halach vinik). Cuentan y "doblan" el $k^{\prime}$ atun, y reciben su insignia de oficio -plato y copa los sacerdotes, estera y trono el señor. Entonces confirman los títulos de las tierras en procesión solemne, y hacen anuncio de la profecía del $k^{\prime} a t u n$. Los oficiales del $k^{\prime} a t u n$ antecedente son retirados al momento de empezar el $k^{\prime} a t u n$. Diez años después, a la mitad del $k^{\prime}$ atun, es el tiempo para el nombramiento de los oficiales del $k^{\prime} a t u n$ siguiente. Resulta que un oficial tenía cargo pú. blico durante no veinte sino treinta años. No es del todo clara la división de deberes para las tres décadas de servicio. Hay, además, otros cargos más breves: por ejemplo, el del oficial identificado con el medio $k^{\prime} a t u n$, quien entra al cuarto y comienza su servicio a la mitad, retirándose a los tres cuartos. Bajo la primacía teórica de Mayapán, trece ciudades servían como sedes del $k^{\prime} a t u n$ en turno. Existía una viva rivalidad para obtener este honor, que tenía gran trascendencia económica y política, formando así un ciclo de casi 260 años entre las 13 ciudades. Es de suponer que había siempre gran actividad política y religiosa hacia el final de cada $k^{\prime}$ atun para el efecto de nombrar la sede subsecuente, junto con los oficiales y sacerdotes.

Claro está, que este esquema ritual del k'atun sólo queda planteado teóricamente. En la realidad, había cambios y alteraciones del orden por toda clase de razones: personales, accidentales, políticas o naturales. La sequía, plagas, guerras y confabulaciones interrumpen la historia maya como a cualquier otra. El $k^{\prime}$ atun del Oxlahun $K^{\prime}$ an estaba perturbado además por la conquista española, y nuestro autor se queja constantemente del desorden de los ritos y sacrificios tradicionales.

Los varios ciclos empleados en el libro de Tizimín ofrecen aún otra perspectiva. Es posible ver, en el $t z o l$ k'in adivinatorio, los restos de una ideología antigua bastante general a toda Mesoamérica, que se remonta hasta la época preclásica, y que está bastante difundida entre la gente común. La ideología del tun y k'atun pertenecen a la etapa de los mayas clásicos, ya por el siglo XVI identificada con los linajes del oriente. El énfasis sobre el hab y el $k^{\prime}$ in tun $y$ abil se debe a los mexicanos y a su influencia posclásica, en 
la época a que nos referimos, los linajes del occidente. Y, finalmente, el año se identifica con los invasores españoles. El juego de los ciclos refleja, entonces, la mezcla de estas influencias en Yucatán en un momento dado.

Parece que el sentido histórico cíclico de los mayas se representa en el texto del Oxlahun $K^{\prime} a n$, no como la historia de un solo período, sino de dos a la vez. Se recuenta la historia glífica de 15411561, precisamente para indicar su importancia y semejanza con la historia de 1593-1613, ó 52 años después. La traducción secundaria $e$ interpretativa del Oxlahun $K^{\prime}$ an nos permite yuxtaponerla con la historia española de estos dos períodos, y ofrece unos puntos de correspondencia interesantísimos, como se verá en el cuadro siguiente.

\section{CONFRONTACIÓN DE FUENTES}

\section{Oxlahun K'an}

$3 K^{\prime} a n$

Profesía de Cristianización.

1 Muluc

Calendario europeo; ley de indumentaria

2 Ix

Guerra religiosa cerca del mar

3 Cauac

Continúa la guerra; llegan misioneros

$4 \mathrm{Kan}$

Vuelta a la religión maya; derrota de 7

Chuah

\section{Fuentes españolas}

1541

Conversión de Tutul Xiu (Ancona 1878:1: 322-3); ocupación de Mérida (Chamberlain 1878:212-3).

1542

Batalla del 11 de junio; conquista de los cupules (Ancona 1878:1:333, 336ff).

1543

Conquista de Uaymil (Chamberlain 1948: 233).

1544

Invasión de Cochuah Vuelta del duende de

(Chamberlain 1948: Valladolid

233).

1545
1593

1594

1595

Conquista de Bahía

Ascensión

1596

(Sánchez de Aguilar 1892:273).

1597

Andrés Chi ejecutado por hereje (Sánchez de Aguilar 1892:290; Ancona 1878:2:28-9). 


\begin{tabular}{|c|c|c|}
\hline Oklahun K'an & Fuentes Espa & ñolas \\
\hline $\begin{array}{l}5 \text { Muluc } \\
\text { Abandono de pueblos }\end{array}$ & $\begin{array}{l}1546 \\
\text { Gran Rebelión Maya; } \\
\text { abandono de pueblos } \\
\text { (Chamberlain 1948: } \\
\text { 240); franciscanos en } \\
\text { Campeche (Ancona } \\
\text { 1878:2:36). }\end{array}$ & 1598 \\
\hline $\begin{array}{l}6 \text { Ix } \\
\text { Continúa la guerra; } \\
\text { resurgimiento maya }\end{array}$ & $\begin{array}{l}1547 \\
\text { Rebelión suprimida en } \\
\text { febrero (Ancona 1878: } \\
2: 36 \text { ); muchos pueblos } \\
\text { abandonados (Cham- } \\
\text { berlain 1948:251). }\end{array}$ & 1599 \\
\hline $\begin{array}{l}7 \text { Cauac } \\
\text { Continúa la rebelión }\end{array}$ & $\begin{array}{l}1548 \\
\text { Franciscanos en Maní } \\
\text { (Ancona 1878:2:49). }\end{array}$ & 1600 \\
\hline $\begin{array}{l}8 \text { Kan } \\
\text { Sequía y guerra }\end{array}$ & $\begin{array}{l}1549 \\
\text { Hambre en Itzamal; } \\
\text { franciscanos en Mérida, } \\
\text { Conkal, Itzamal (Anco- } \\
\text { na } 1878: 2: 71 \text { ). }\end{array}$ & 1601 \\
\hline $\begin{array}{l}\text { 9 Muluc } \\
\text { Paz }\end{array}$ & 1550 & $\begin{array}{l}1602 \\
\text { Conversión pacífica } \\
\text { de Bahía Ascensión } \\
\text { (Ancona 1878:2: } \\
195-6 \text { ). }\end{array}$ \\
\hline $\begin{array}{l}10 \mathrm{Ix} \\
\mathrm{Paz}\end{array}$ & 1551 & 1603 \\
\hline $\begin{array}{l}\text { 11 Cauac } \\
\text { Misioneros; guerra }\end{array}$ & $\begin{array}{l}1552 \\
\text { Franciscanos en Valla- } \\
\text { dolid (Ancona 1878:2: } \\
72 \text { ). }\end{array}$ & 1604 \\
\hline $\begin{array}{l}12 \mathrm{Kan} \\
\text { Cristianismo; sacrifi- } \\
\text { cios }\end{array}$ & 1553 & $\begin{array}{l}1605 \\
\text { Idolatría en Chance. } \\
\text { note (Sánchez de } \\
\text { Aguilar 1892:310). }\end{array}$ \\
\hline $\begin{array}{l}13 \text { Muluc } \\
\text { Sacrificios }\end{array}$ & 1554 & 1606 \\
\hline
\end{tabular}




\begin{tabular}{lc}
\hline \hline Oxlahun K'an & Fuentes Españolas \\
\hline I Ix & \multirow{2}{*}{1555} \\
Sacrificios; guerra & 1607 \\
& Lluvia de sangre en \\
& Valladolid, Tixcacal; \\
& ídolos en Tizimín \\
& (Sánchez de Aguilar \\
$1892: 270,311)$.
\end{tabular}

2 Cauac

1556

1608

Resurgimiento maya

$3 \mathrm{Kan}$

1557

1609

Suspensión de títulos de tierras

4 Muluc

Sacrificios

1558

Epidemia (Means

1917:55).

Idolatría en Valladolid Rebelión en Tekax

(Ancona 1878:2:200

1; Sánchez de Agui-

lar 1892:290; Means

1917:55); herejía de

Francisco Canul, Al-

fonso Chablé (Sánchez de Aguilar 1892: 303).

5 Ix

1559

1611

Rechazo del santo por la gente del lago

Comienzo de la cate-

La embajada de los Itzá a Mérida en (Roys, s. f.: 29); sacri- 1614?

ficios en Hocabá.

6 Cauac

Sacrificios

$7 \mathrm{Kan}$

División de oriente y occidente
1560

Duende de Valladolid

(Sánchez de Aguilar 1892:271; idolatría en Tepich.

1561

Landa provincial; castigo de Maní (Áncona 1878:2:76-8).

1612

Hasta cierto punto, podemos decir que este cuadro ofrece una perspectiva española y mexicana de la historia tratada. Claro que los historiadores españoles se preocuparon mucho más por sus propias entradas y por la política civil y eclesiástica de la colonia naciente. 
Para los mexicanos era más bien la repetición del ciclo de 52 años lo que les captó la atención. Pero queda también una tercera perspectiva: la del oriente o de la tradición itzá, también parcialmente mexicanizada, pero más cercana a la actitud propiamente maya $\mathrm{y}$, por eso, enfocada en el K'atun.

La expresión de esta tercera posición ocasiona que los mismos acontecimientos históricos se presenten como una guerra civil maya, $u$ k'atun k'atunob, o guerra de los k'atunes, que hasta llega a ser guerra de clases: la nobleza oriental contra la despreciada occidental, contra el campesinado, contra el mexicanismo y contra la cristiandad. Hasta durante los períodos de tranquilidad relativa con los españoles, esta guerra subterránea continuó representándose como una lucha sobre los ritos y hasta sobre el ciclo mismo del $k^{\prime} a t u n$.

Nuestro texto presenta el $k^{\prime} a t u n$ en forma algo confusa. Pero bajo la confusión se puede reconocer el ciclo clásico. Esquemáticamente se puede representar así:

(1588 Atado el cargo de 5 Ahau)
1593 Toma del plato de 5 Ahau
1599 Asentado 5 Ahau; retiro de 7 Ahau
1604 Toma de máscara de 5 Ahau
1609 Atado el cargo de 3 Ahau
(1614 Toma del plato de 3 Ahau)
(1619 Asentado 3 Ahau; retiro de 5 Ahau)

Puesto que nuestra crónica sólo trata de 1593 a 1613, no cubre todo el ciclo del k'atun 5 Ahau (1599-1619), a pesar de implicar que lo ha hecho. La razón es obvia por haber habido tantas peleas que interrumpieron en repetidas ocasiones la continuidad de los ritos.

$\mathrm{La}$ actitud de nuestro autor respecto a tales desventuras está enteramente clara. Tacha de sodomitas a los señores cristianizantes, y a la gente vulgar le dice, en efecto: "ique se vayan a ser esclavos! ¡Éste no es el momento para abandonar la tradición noble y sagrada de los antepasados!"

Creo haber demostrado que el texto del Oxlahun K'an 5 Ahau nos ofrece datos ricos y vivos, hasta ahora insospechados, sobre la historia colonial maya. Es, a la vez, innegable que es un texto sumamente difícil, florido, ambiguo $\mathrm{y}$, a veces, intencionalmente oscuro. Promete, sin embargo, proporcionarnos todo un mundo de aclaraciones sobre lo que fue la historia maya, tal como lo experimentaron los mismos mayas. 


\section{Notas al Tizimín}

1. La cronología del Oxlahun $K^{\prime} a n$ corresponde a la clásica, y a la de GoodmanMartínez-Thompson corregida por Thompson en 1958; pero difiere en cuatro detalles: (1) Cuenta el cargador del año en 1 Pop en vez de O Pop; (2) emplea Kan, Muluc, Ix y Cauac como cargadores; (3) cuenta los días y los katunes por el comienzo, y no por el fin; y (4) no corrige para los bisiestos, sino que se apega a la correspondencia de 1 Kan 1 Pop con el 16 de julio de 1581 . El documento dá la profecía para una veintena de 1593-1613, pero con base en una historia glífica de 1541-1561, según nos dice el mismo autor. Terminó de escribirse el 9 de febrero de 1596 (juliano), en Chetumal, por un sacerdote llamado Kauil Ch'el. Los aspectos calendáricos del manuscrito están descritos en otra parte (Edmonson, s. f.).

3. El ciclo de los ritos de un k'atun determinado comenzó con "atarle su cargo", diez años antes del comienzo del k'atun mismo. Para el k'atun 5 Ahau, esto habrá ocurrido en 1588. La segunda etapa es "la toma del plato", en este caso 1593. El verdadero comienzo del k'atun es el lubul o "descanso", que implica también "estacionamiento". Esto se llama, también, "asentar al k'atun". K'atun 5 Ahau comenzó en 1599. A los cinco años, "recibe la máscara" de los Bacab (1604); a los diez, le "ata el cargo" a su sucesor (1609); a los quince, "se dobla el k'atun" (1614) y, a los veinte, "toma su camino" (1619) al lubul de su sucesor, participando, según parece, en el "paseo del k'atun" en que se confirman los títulos de tierras. El sacerdote retirado parece haber desempeñado su oficio durante cinco años más, pero esto no es claro. El presente texto indica que el acto final consistió en "terminar su palabra" el k'atun antecedente (7 Ahau), antes de "atarle el cargo" al subsecuente (3 Ahau). En este caso fue hecho, "correctamente", en 1602.

5. El año comenzó en $13 K^{\prime} a n$ O Pop en la notación normal. Era de esperarse aquí una fecha 16 Tzek en el manuscrito, pero parece que nombra la víspera, 4 Kavak 15 Tzek, cuando "amaneció". Hay 96 días de 13 K'an a 5 Ahav.

10. Frecuente aquí es la copla k'inil-uil 'período del sol-período de luna', con la implicación de que el sol comienza lo que termina la luna. La inversión del orden es bastante significativa.

11. Con frecuencia, el yucateco emplea partículas de incertidumbre (hi), como expresión nada más de cortesía, modestia o elegancia. Sin embargo, leo aquí he, 'esto'.

13. Mayapán, 'lugar del ciclo', es indicado comúnmente como "sede del ciclo" (may ku). Fue el 'asiento' (hets') del k'atun 7 Ahau, pero Sots'il lo fue del k'atun 5 Ahau, según el Chumayel. Otras partes del Tizimín están de acuerdo. Mayapán mantenía siempre cierta primacía de centro, tanto intelectual como geográfico.

18. Al k'uk', 'hijo de madre quetzal'; al yaxum 'hijo de madre paloma'. La omisión de referencia al hijo varón de hombre indica diferenciación en el modo de contar el parentesco; incluso implica la ilegitimidad.

22. Al-mehen, 'hijo de madre-hijo varón de padre', es la referencia más usada para la nobleza, correspondiendo al uso típico de los mayas postoltecas. 


\section{Notas al Tizimín}

1. La cronología del Oxlahun K'an corresponde a la clásica, y a la de GoodmanMartínez-Thompson corregida por Thompson en 1958; pero difiere en cuatro detalles: (1) Cuenta el cargador del año en 1 Pop en vez de O Pop; (2) emplea Kan, Muluc, Ix y Cauac como cargadores; (3) cuenta los días y los katunes por el comienzo, y no por el fin; y (4) no corrige para los bisiestos, sino que se apega a la correspondencia de 1 Kan 1 Pop con el 16 de julio de 1581. El documento dá la profecía para una veintena de 1593-1613, pero con base en una historia glífica de 1541-1561, según nos dice el mismo autor. Terminó de escribirse el 9 de febrero de 1596 (juliano), en Chetumal, por un sacerdote llamado Kauil Ch'el. Los aspectos calendáricos del manuscrito están descritos en otra parte (Edmonson, s. f.).

3. El ciclo de los ritos de un k'atun determinado comenzó con "atarle su cargo", diez años antes del comienzo del k'atun mismo. Para el k'atun 5 Ahau, esto habrá ocurrido en 1588. La segunda etapa es "la toma del plato", en este caso 1593. El verdadero comienzo del k'atun es el lubul o "descanso", que implica también "estacionamiento". Esto se llama, también, "asentar al k'atun". K'atun 5 Ahau comenzó en 1599. A los cinco años, "recibe la máscara" de los Bacab (1604); a los diez, le "ata el cargo" a su sucesor (1609); a los quince, "se dobla el k'atun" (1614) y, a los veinte, "toma su camino" (1619) al lubul de su sucesor, participando, según parece, en el "paseo del k'atun" en que se confirman los títulos de tierras. El sacerdote retirado parece haber desempeñado su oficio durante cinco años más, pero esto no es claro. El presente texto indica que el acto final consistió en "terminar su palabra" el k'atun antecedente (7 Ahau), antes de "atarle el cargo" al subsecuente ( 3 Ahau). En este caso fue hecho, "correctamente", en 1602.

5. El año comenzó en $13 K^{\prime} a n$ O Pop en la notación normal. Era de esperarse aquí una fecha 16 Tzek en el manuscrito, pero parece que nombra la víspera, 4 Kavak 15 Tzek, cuando "amaneció". Hay 96 días de 13 K'an a 5 Ahav.

10. Frecuente aquí es la copla k'inil-uil 'período del sol-período de luna', con la implicación de que el sol comienza lo que termina la luna. La inversión del orden es bastante significativa.

11. Con frecuencia, el yucateco emplea partículas de incertidumbre ( $h i)$, como expresión nada más de cortesía, modestia o elegancia. Sin embargo, leo aquí he, 'esto'.

13. Mayapán, lugar del ciclo', es indicado comúnmente como "sede del ciclo" (may ku). Fue el 'asiento' (hets') del k'atun 7 Ahau, pero Sots'il lo fue del k'atun 5 Ahau, según el Chumayel. Otras partes del Tizimín están de acuerdo. Mayapán mantenía siempre cierta primacía de centro, tanto intelectual como geográfico.

18. Al k'uk', 'hijo de madre quetzal'; al yaxum 'hijo de madre paloma'. La omisión de referencia al hijo varón de hombre indica diferenciación en el modo de contar el parentesco; incluso implica la ilegitimidad.

22. Al-mehen, 'hijo de madre-hijo varón de padre', es la referencia más usada para la nobleza, correspondiendo al uso típico de los mayas postoltecas. 
26. No logro localizar $A k^{\prime} a b$ P'ex; hay muchos Yaxché en Yucatán. Posiblemente es el Yaxché, unos kilómetros al norte de Chichén Itzá, el que está en juego aquí.

29. Según el mismo Tizimín, este año $13 K^{\prime} a n$ era el decimotercero de los que están orientados hacia el oriente con color rojo. El año siguiente inicia otra trecena orientada hacia el norte con color blanco. Al norte de Tizimín (y único puerto que solía servir de sede al k'atun), queda Emal.

32. "Trazar el paso del k'atun" es parte ritual del inicio del año. Adivino que aquí los chak están identificados con los cargadores del año.

33. Está implicado que son los chak los que se paran en la plaza.

37. La segunda mitad del k'atun 11 Ahau, según la cronología del presente manuscrito, corresponde a los años 1549-1559. La profecía está inserta aquí para "predecir" la verdadera entrada de los misioneros, lo que está descrito abajo precisamente para el año 1596 (=1544). K'atun 11 Ahav está regularmente identificado como k'atun de la flor. Otros "apodos" semejantes de los k'atunes pueden identificarse, aunque con menos seguridad:

$\begin{array}{rll}13 \text { Ahav } & (?) \\ 11 \text { Ahav } & \text { Flor } \\ 9 \text { Ahav } & \text { ¿Cera? } \\ 7 \text { Ahav } & \text { ¿Venado? } \\ 5 \text { Ahav Pájaro } \\ 3 \text { Ahav } & \text { ¿Negro? } \\ 1 \text { Ahav } & \text { ¿Pedernal? } \\ 12 \text { Ahav } & \text { Mono } \\ 10 \text { Ahav } & \text { (?) } \\ 8 \text { Ahav } & (?) \\ 6 \text { Ahav } & (?) \\ 4 \text { Ahav } & \text { Tortuga } \\ 2 \text { Ahav (?) }\end{array}$

42. K'in ich, 'ojo (o cara) del sol', implica héroe o dios brillante. Ah chaan te, 'él del arbolito', se refiere a la cruz.

\section{BIBLIOGRAFIA}

Sánchez de Aguilar, Pedro

1892 Informe contra indolorum cultores. En Francisco Paso y Troncoso (Ed.) Tratado de las idolatrías, supersticiones, dioses, ritos, hechicerías y otras costumbres gentílicas de las razas aborígenes de México: 181-329. Editorial Fuente Cultural, México.

Ancona, Eligio

1878 Historia de Yucatán. 3 vols., M. Heredia Argüelles, Mérida.

\section{Means, Philip Ainsworth}

1917 History of the Spanish Conquest of Yucatan and the Itzas. Papers of the Peabody Museum 7. 
Chamberlain, Robert S.

1948 The Conquest and Colonization of Yucatan, 1517-1550. Carnegie Institution of Washington Publication 582, Washington.

Roys, RaLPh L.

s.f. Book of Chilam Balam of Tizimin. Transcription and notes, typescript, in Latin American Library, Tulane University, New Orleans.

1965 Book of Chilam Balam of Chumayel. University of Oklahoma Press, Norman.

Garibay K., Angel María

1953 Historia de la Literatura Náhuatl. 2 vols., Edit. Porrúa, México, (Biblioteca Porrúa, 1). 